\title{
Assessing Energy Efficiency of Port Operations in China-A Case Study on Sustainable Development of Green Ports
}

\author{
Haibo Wang', Da Huo ${ }^{2}$, Jaime Ortiz \\ ${ }^{1}$ Sanchez School of Business, Texas A\&M International University, Laredo, TX, USA \\ ${ }^{2}$ School of International Trade and Economics, Central University of Finance and Economics, Beijing, China \\ ${ }^{3}$ Office of Provost, University of Houston, Houston, TX, USA \\ Email: hwang@tamiu.edu, dhuo@cufe.edu.cn, jortiz22@central.uh.edu
}

Received 15 April 2015

\begin{abstract}
Recent joint report by World Bank Group and development research center of the State Council of China pointed out the importance of sustainable development of infrastructure in China. However, the most recent report by Natural Research Defense Council (Oct 0214) indicated that only a few port cities in China paid attention to the air pollution from ship and port activities. This study reports the finding of assessing energy efficiency of port operations in China based on the data from public domains by using the combination of Data Envelopment Analysis (DEA) and Panel Data Estimation (PDE). This study also exams the gap between the proposed green port evaluation index and actual guideline of port operations by local government. The aim of this study is to report the effectiveness of sustainable development policy and highlight the workable plans on improving energy efficiency with financial success.
\end{abstract}

\section{Keywords}

Energy Efficiency, Pollution, Sustainable Development, Infrastructure, Green Ports, Data Envelopment Analysis, Panel Data Estimation

\section{Introduction}

Transportation infrastructure including sea, land and air ports provides the backbone of global supply chain and logistics. They are key components of economic network in the global business environment. Among them, Sea ports are considered as the critical nodes in the global trade network. However, the emission from the shipping vehicles such as container ship, truck and cargo plane, created severe air pollution problems, especially developing countries. Even in the developed countries in North America and Europe, very little attention was given to study the long term environmental impact in the port construction and operations until recently. It is important to have the collaboration among academy, industry and government agencies on solving this highly challenged problem. For example, the "Green Port Congress" annual conference has been hosted by different nations and attracted decision makers from different areas to share information on sustainable development and introduce 
innovation to create a "green" global supply chain and logistics environment.

In the last three decades, China gradually becomes the largest manufacturing nation in the world and the development of ports in China is unprecedented comparing to other emerging markets. According to the report from Natural Resource Defense Council (NRDC), 50\% of the largest 20 sea ports in the world are located in China. Among them, 70\% of the busiest 10 sea ports are managed by Chinese port authorities [1]. The report also points out the low quality of bunk fuel which powers the ship and the low grade of diesel fuel is the major sources of pollution in the Chinese ports and surrounding cities. The emission of these dirty fuels not only creates a high emission of particulate matter (PM) which is a key source of severe air pollution episodes in recent years, but also threatens human health to cause premature deaths. The low cost of dirty fuels is a main factor to use in the transportation without the consideration of shortening the lifespan of commercial vessels and vehicles. In China, the spending on cleaning the environment was not the outcome measured by GDP growth and it might discourage local government officials to enforce the policy on reducing the emission of dirty fuels. However, the loss of productivity due to the human health issues might exceed the spending on using clean fuels according to NRDC study. In the meantime, the competition of port operations on container volume is intensified while China will attract more container loading with the new established free trade zones and new deep sea ports. The intensified competition and the new economic development policy on the silk-road economic development belt from Chinese government will lead to more shipping traffic to the Chinese ports and potentially more pollution problems. According to the international seaborne trade data from the United Nations Conference on Trade and Development (UNCTAD), China ranks $1^{\text {st }}$ " “Containerized Imports and Exports” in term of seaborne trade volume and growth in the last five years and has ten-folder increase in the Intra-Asia trade since 2002. However, US ranks $1^{\text {st }}$ in the total trade volume using more advanced intermodal network and ahead of China in the landside and air transportation. The fuel quality of diesel in the commercial vehicles is also higher than developing countries and cleaner energy such as electricity power, bio-fuel and natural gas are introduced to reduce the emission. The difference in the quality of fuel can bring challenges in the cross-border transportation including seaborne trade and different policies and regulations of emission among countries can create an operational complexity. Ocean liners have to switch fuels for different destinations and the operation efficiency will decrease in term of the fuels economic because fuel cost is a significant part of Ocean liners' transportation spend.

Recent joint report by World Bank Group and Development Research Center of the State Council of China pointed out the importance of sustainable development of infrastructure in China [2]. In this report, a strategy of reform on sustainable development is centered on the efficiency measured by the sustainable outcomes instead of the traditional economic growth outcomes. It proposed a reform agenda focusing on sustainable development on land management to promote greener urbanization. However, the most recent report by Natural Research Defense Council (Oct 0214) indicated that only a few port cities in China paid attention to the air pollution from ship and port activities [1].

The remainder of the paper is organized as follows: the reviews on sustainable development of ports and energy efficiency are discussed in the next session, followed by the research methods used in this study. The implementation of the research method is reported in Session 4 and finally, the conclusion and future development are presented.

\section{Sustainable Development of Ports and Energy Efficiency}

\subsection{Sustainable Development of Ports}

The disruptive technologies in the last fifty years such as PC, Internet, Email, Smartphone, Cloud Computing and Social network, have fueled the fast growth of global business and international trade. More seaports are built to facility the increasing demand on international trade and cross-border commerce. When Water discussed the economic impact of ports in his 1977 study, the issue of sustainable development is not the major objective in the design and construction. Researchers began to pay attention on sustainable development of ports and reported a number of case studies of sustainable development on the seaports of different countries in term of operational efficiency [3]-[15]. Some researchers proposed the assessing criteria on sustainable outcomes and the classification methods of green ports [4] [7] [10] [11] [16]-[18]. Researchers reported the optimal layout of the ports, fast turnaround in shipping, and the optimal schedule of loading on the terminal as key factors of operation efficiency [19]-[21]. The sustainability principles should be implemented in the processes of design, con- 
struction and operations. The practice of green port and efficiency measurement in the developed economic should be good inspiration to the emerging markets [19].

\subsection{Operations of Major Chinese Sea Ports}

There are 172 ports in China and 32 of them can provide service to container liners (see Figure 1). In our previous study, we investigated 11 ports that are listed in the Chinese stock market and studied the relative operation efficiency of the 11 ports based on the key financial ratios.

New ports and terminals constructed in the last few years and many existing ports are also expanding to accommodate the growth of international trade and cross-border e-commerce. Many Chinese ports are operated by the state owned companies and monitored or regulated by different levels of local government. Hence the policy of local government has major impact on the sustainable development of the ports. The newly established free trade zones have also added complexity to develop the sustainable policy because the free trade zones are under guidance from both central and local government offices.

\subsection{Green Ports Evaluation Index}

In other industrial areas such as manufacturing and construction, the leadership in Energy and Environmental Design (LEED) program standard is adopted to measure the emission of greenhouse gas in the buildings. Businesses employ various practices to receive LEED certification and label themselves as green business. Organizations such as UN Department of Economic and Social Affairs have published guidelines of sustainable development on transportation. However, there is no worldwide standard of green ports index or certification. Pak, Yeo and Coo presented an empirical study based on the survey of port authorities and reported a 5 dimensional index with 15 variables [4]. The 5 dimensions are identified by a factor analysis procedure in the study.

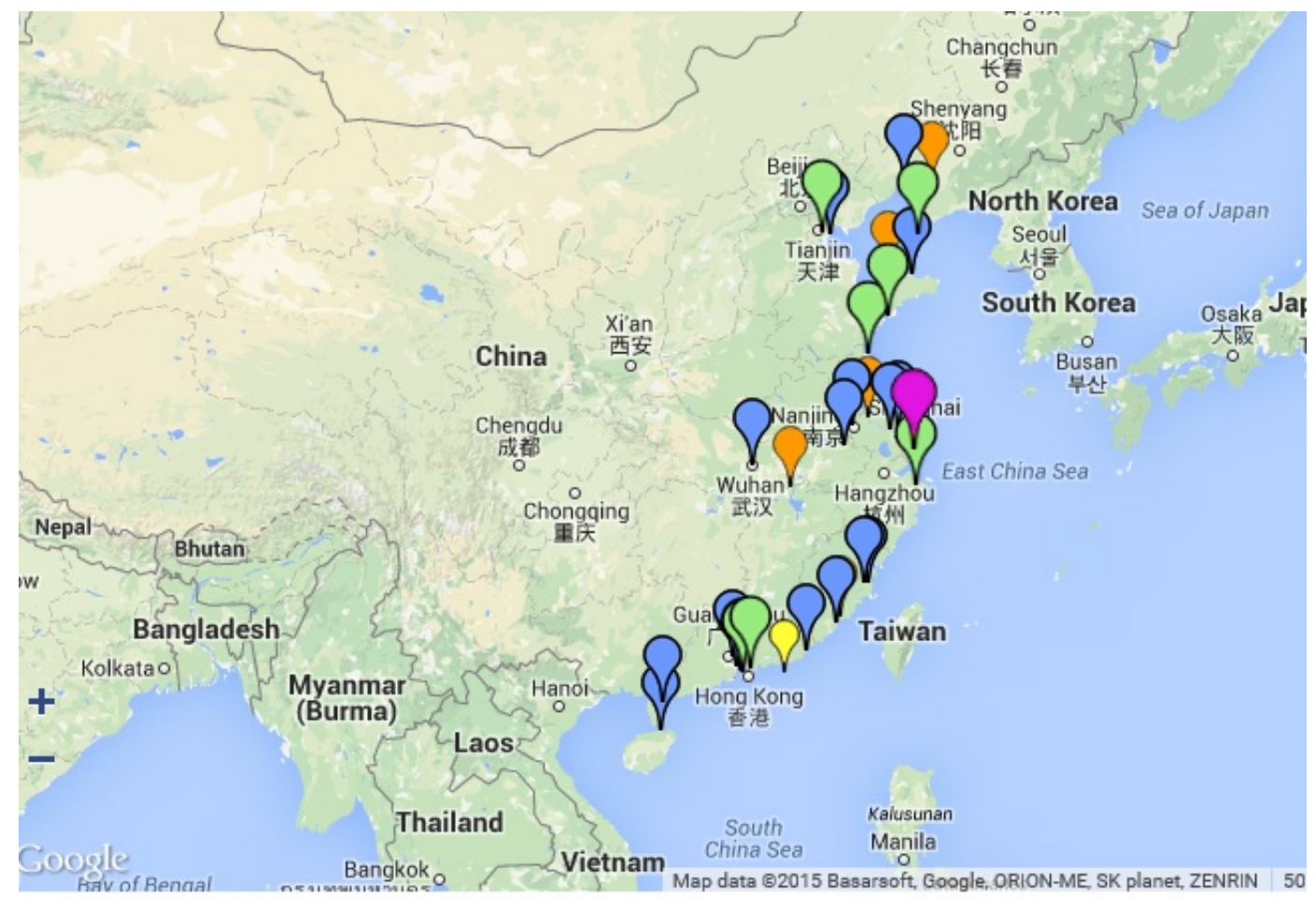

Port icons are color coded by size.

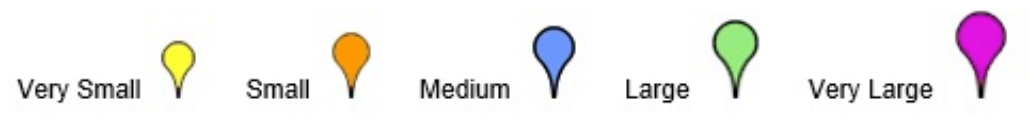

Figure 1. Seaborne ports of China provided by worldportsource.com. 


\section{Research Methods}

Recently, researchers reported a few studies on assessing the factors of green ports and operation efficiency. Chiu et.al reported a fuzzy AHP analysis approach on green port factors and performance [22], they assessed five dimensions and 13 factors in the port operations. AHP is reported as an effective method on ranking factors. They also reported a case study on three seaports in Taiwan and analyzed the best practices in green port operations. L and Yang also presented a study on assessing operation efficiency using AHP and Fuzzy logic [6]. In this study, we presented a two-steps approach: evaluation and selection. The evaluation process of assessment data is based on an extension of the data envelopment analysis (DEA) model and Panel Data Estimation (PDE).

\subsection{Data Envelopment Analysis}

Data Envelopment Analysis (DEA) is an effective and easy to be implemented method on assessing the operation efficiency. Researchers applied DEA to study the efficiency in many areas including education, financial service, supply chain management, and logistics. The basic model of DEA in this study is described in Figure 2.

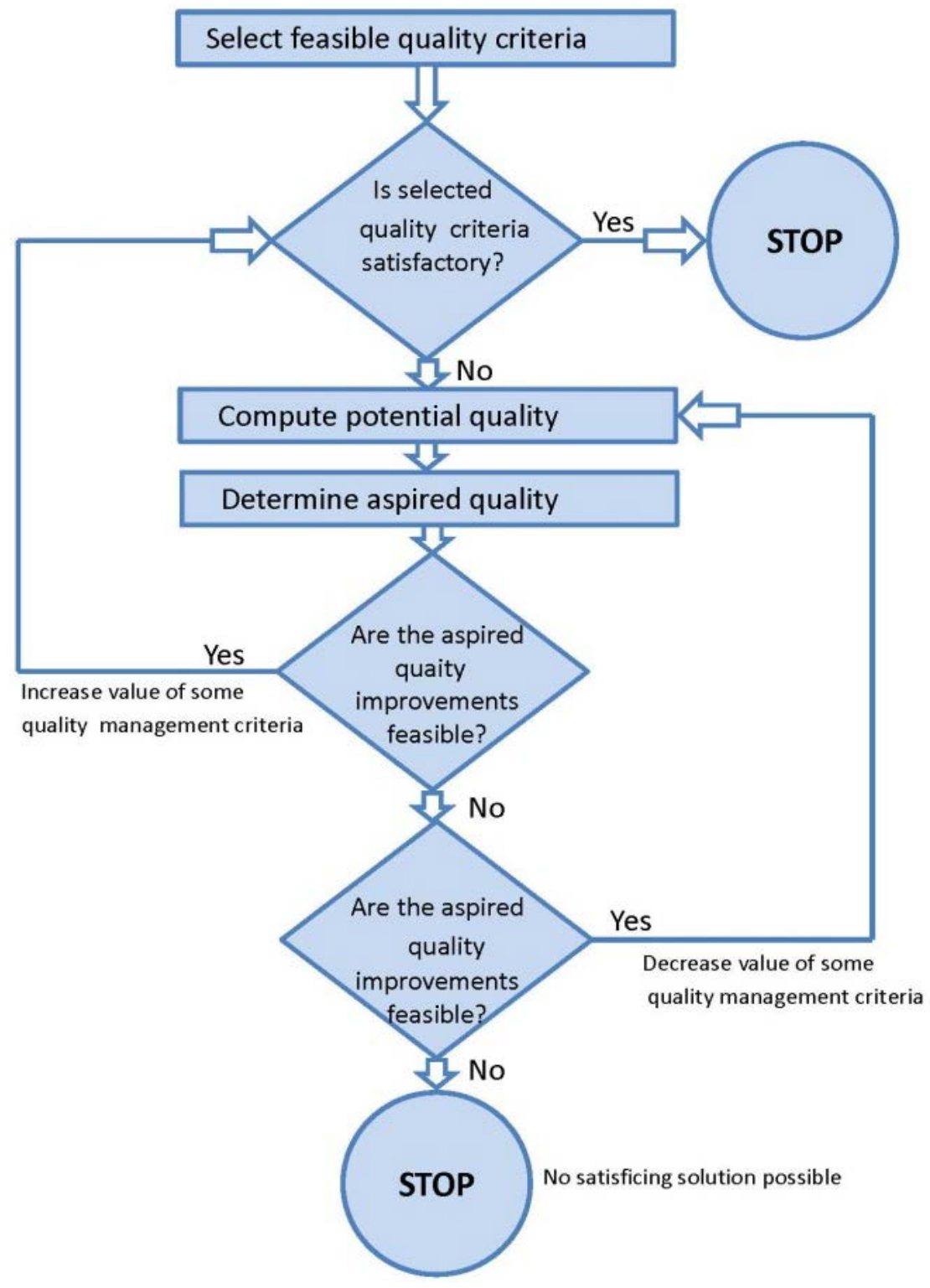

Figure 2. DEA model for evaluation of variables in assessment. 


\subsection{Panel Data Estimation}

Panel Data Estimation (PDE) is often applied to the study with time series data or data aggregated in the time or space dimension. The basic PDE model can be presented as:

$$
y_{i, t}=\delta_{i, t}+\alpha \cdot y_{i, t-1}+\theta_{i}+\beta v_{i, t}
$$

where $\delta_{i, t}$ is a random disturbance, $\theta_{i}$ is a fixed-effect, and $v_{i, t}$ is a vector of exogenous regressors. The estimator $y_{i, t}$ could performs well when the time dimension $t$ of the PDE is large. PDE is used to measure the cross-sectional effect of energy efficiency in the port operations.

\subsection{Selection of Factors for Assessment}

There are many factors to measure the operation efficiency and the aim of the selection process is to find the optimal sets of factors for building accurate assessment model. The selection process involves two conflicting objectives. Researcher would like to include more factors in the model but the collinearity among the factors can decrease the predictive power. For a given subset of factors $x_{i}$ and its estimators $y$, let $\mu_{y i}$ be the sample correlation coefficient between factors and estimator, and $\mu_{i j}$ be the sample correlation coefficient between factors $x_{i}$ and $x_{j}$. The selection process can be presented as:

$$
\text { Maximize } \alpha \sum_{\substack{i=1 \\ i \in N}}^{n}\left|\mu_{y j}\right| x_{i}-(1-\alpha) \sum_{\substack{i=1 \\ i, j \in N, i<j}}^{n-1}\left(\left|\mu_{i j}\right|+\left|\mu_{j i}\right|\right) x_{i} x_{j} \text { s.t. } x_{i}, x_{j} \in\{0,1\}
$$

where $x_{i}=1$ if factor is in subset, 0 otherwise. The factors chosen by this nonlinear model will be used to construct the index and validated by several classification methods.

\section{Computation and Implementation}

In this study, the DEA and PDE models are implemented under the open-source computing environment. The data is collected from public domain such as the financial ratios from company reports, the trade data from UNCTAD website and World Shipping Council. The data on emission policy and regulation is acquired from the port-city government and National Bureau of Environmental Protection and is abstracted with the opensource text mining software. All analytic models and text mining tools are implemented in R software, which is an open-source cross-platform programming language with a platform adaptive run-time environment for statistical computing and graphics. There are more than 3500 application/function based packages developed by worldwide researchers and widely used for a variety of statistical models including statistical tests, linear and non-linear models, time series forecasting, data mining and predictive analytics, etc. It provides a collaborative environment for new applications or functions to be added on as a cross-platform library.

\section{Conclusion and Future Development}

This study reports a framework of assessing energy efficiency of port operations in China based on the data from public domain by using the combination of DEA and PDE. This study also exams the gap between the proposed green port evaluation index and actual guideline of port operations by local government. In addition, the deployment of in-vehicle computer and control system laid the foundation of emission reduction strategies in the era of small technology. The advance of intelligent logistics and smart transportation can improve the fuel economic using remote sensing and big data analytics. The fuel economic is key to the business on choosing cleaner energy instead of the dirty fuel. To follow up the study on relative efficiency of public-listed ports in China, we will add the factors of sustainable outcomes in addition to the financial ratios and report the prediction of long term development on these ports in China.

\section{Acknowledgements}

This research was supported in part by Sanchez School of Business and Texas A \& M International University Research Grant. 


\section{References}

[1] Council, N.R.D. (2014) Prevention and Control of Shipping and Port Air Emissions in China.

[2] World Bank and Development Research Center of the State Council of the People's Republic of China (2014) Urban China: Toward Efficient, Inclusive, and Sustainable Urbanization. World Bank, Washington DC.

[3] González, M.M. and Trujillo, L. (2009) Efficiency Measurement in the Port Industry: A Survey of the Empirical Evidence. Journal of Transport Economics and Policy (JTEP), 43, 157-192.

[4] Pak, J.-Y., Yeo, G.-T. and Coo, B. (2009) A Study on Selecting Green Indexes of a Seaport. International Journal of Navigation and Port research, 33, 653-657.

[5] Esmemr, S., Ceti, I.B. and Tuna, O. (2010) A Simulation for Optimum Terminal Truck Number in a Turkish Port Based on Lean and Green Concept. The Asian Journal of Shipping and Logistics, 26, 277-296.

[6] Li, T.-G. and Yang, B. (2010) Study on Green Logistics Operation System of Port Based on AHP-Fuzzy Comprehensive Evaluation. 2010 2nd International Conference on Industrial and Information Systems (IIS), 1, 175-178.

[7] Notteboom, T. (2010) The Role of Intermodal Transport and Inland Terminals in "green” Port Strategy: Experiences from Europe. World Ocean Forum.

[8] Wu, Y.-C.J. and Goh, M. (2010) Container Port Efficiency in Emerging and More Advanced Markets. Transportation Research Part E: Logistics and Transportation Review, 46, 1030-1042. http://dx.doi.org/10.1016/j.tre.2010.01.002

[9] Chang, C.-C. and Wang, C.-M. (2012) Evaluating the Effects of Green Port policy: Case Study of Kaohsiung Harbor in Taiwan. Transportation Research Part D: Transport and Environment, 17, 185-189.

[10] Lam, J. and Notteboom, T. (2012) The Green Port Toolbox: A Comparison of Port Management Tools Used by Leading Ports in Asia and Europe. International Association of Maritime Economists (IAME) Conference, Taipei, September 2012.

[11] Lam, J.S.L. and van de Voorde, E. (2012) Green Port Strategy for Sustainable Growth and Development. Transport Logistics for Sustainable Growth at a New Level, International Forum on Shipping, Ports and Airports (IFSPA), 2730.

[12] Nikitakos, N. (2012) Emissions Port. FME Transactions, 40, 201-206.

[13] Wang, K., Ng, A.K., Lam, J.S.L. and Fu, X. (2012) Cooperation or Competition \& Quest; Factors and Conditions Affecting Regional Port Governance in South China. Maritime Economics \& Logistics, 14, 386-408. http://dx.doi.org/10.1057/mel.2012.13

[14] Chang, Y.-T., Song, Y. and Roh, Y. (2013) Assessing Greenhouse Gas Emissions from Port Vessel Operations at the Port of Incheon. Transportation Research Part D: Transport and Environment, 25, 1-4. http://dx.doi.org/10.1016/j.trd.2013.06.008

[15] Dooms, M., Haezendonck, E. and Valaert, T. (2013) Dynamic Green Portfolio Analysis for Inland Ports: An Empirical Analysis on Western Europe. Research in Transportation Business \& Management, 8, 171-185.

[16] Peris-Mora, E., Orejas, J.D., Subirats, A., Ibáñez, S. and Alvarez, P. (2005) Development of a System of Indicators for Sustainable Port Management. Marine Pollution Bulletin, 50, 1649-1660. http://dx.doi.org/10.1016/j.marpolbul.2005.06.048

[17] Abood, K.A. (2007) Sustainable and Green Ports: Application of Sustainability Principles to Port Development and Operation. Ports 2007 Conference, ASCE. http://dx.doi.org/10.1061/40834(238)60

[18] Corbett, J.J., Winebrake, J.J., Green, E.H., Kasibhatla, P., Eyring, V. and Lauer, A. (2007) Mortality from Ship Emissions: A Global Assessment. Environmental Science \& Technology, 41, 8512-8518. http://dx.doi.org/10.1021/es071686z

[19] Lee, D.-H., Cao, Z. and Meng, Q. (2007) Scheduling of Two-Transtainer Systems for Loading Outbound Containers in port Container Terminals with Simulated Annealing Algorithm. International Journal of Production Economics, 107, 115-124. http://dx.doi.org/10.1016/j.ijpe.2006.08.003

[20] Zhao, F.-M., Wang, D.-Z. and Wei, X. (2007) Strategic Environment Assessment of General Layout Planning of Port. Environmental Science \& Technology, 7, 22.

[21] Johnson, H. and Styhre, L. (2015) Increased Energy Efficiency in Short Sea Shipping Through Decreased Time in Port. Transportation Research Part A: Policy and Practice, 71, 167-178.

[22] Chiu, R.-H., Lin, L.-H. and Ting, S.-C. (2014) Evaluation of Green Port Factors and Performance: A Fuzzy AHP Analysis. Mathematical Problems in Engineering, 2014. 